\title{
Isostasy, LAB and some properties of asthenosphere in chosen regions of Poland
}

\author{
Leszek Czechowski \\ Institute of Geophysics \\ University of Warsaw
}

U1. Pasteura 5, 02-093 Warszawa. POLAND

Tel. +48225532003 E-mail: lczech@op.pl

\begin{abstract}
We use programs from the package LABWA2015 to determine position of LithosphereAsthenosphere Boundary (LAB) and some properties of lower lithosphere in chosen sites in Poland. Seismic, topographic, thermal and petrological data are used together with assumption about isostasy. Moreover we investigate the role of assumption about the steady state temperature distribution. We have found that sometimes this assumption for continental lithosphere can be unjustified but usually does not lead to significant errors. We have found also that in chosen sites, the thermal LAB is in the depth range $85-95 \mathrm{~km}$. The average value of thermal conductivity of mantle is $\sim 4 \mathrm{~W} \mathrm{~m}^{-1} \mathrm{~K}^{-1}$. Just below MOHO, a level of approximate isostatic compensation is found. More precise compensation is found in the asthenosphere at $\sim 110 \mathrm{~km}$ but its position is sensitive to the density distribution.
\end{abstract}

Key words: asthenosphere, lithosphere, isostasy, compensation, LAB

\section{Introduction}

Many types of data are used to determine the thermal conditions in the Earth's lithosphere e.g. Grinc et al. (2014), Geissler et al. (2010), Tesauro et al. (2009), Hamza and Vieira (2012), Priestley and McKenzie (2013), Fullea et al. (2006), Puziewicz et al. (2019). They were using 


\section{Preprint}

various data: seismic data, petrological data, heat flow data, etc. Eventually, they obtained reliable results for the depth range studied.

However, some of papers treating about thermal conditions in the lithosphere do not use some possible constrains (e.g., assumptions about isostasy), some use too far-reaching simplifications (e.g., when calculating the temperature distribution) or limit their considerations (e.g., considering only the upper lithosphere). Taking into account these remarks could lead to better models of the lithosphere or a better determination of position of LAB (Lithosphere-Asthenosphere Boundary).

In the present paper, we determine the position of LAB and some properties of the lower lithosphere and asthenosphere in a few chosen sites in Poland. Seismic, topographic, thermal and petrological data are used together with assumption about isostasy. Moreover, we investigated the role of assumption about the steady state temperature distribution for the continental lithosphere. For this purpose, we use some of the options offered by LABWA2015 package - Czechowski (2018).

According to our best knowledge, this is the first approach (for the considered sites) that use the assumption about isostasy together with the full equation of thermal conduction and some other geophysical data to determine the position of LAB and some parameters of the uppermost mantle.

\section{Equations and methods}

The package LABWA2015 uses data about gravity (geoid), topography and thermal properties of the lithosphere and the asthenosphere. It also uses the assumption that the lithospheric blocks are in isostatic equilibrium. Similar methods were presented by Krysinski et al. (2013, 2015), Grinc et al. (2014), Fullea et al.(2006). However, LABWA2015 uses a different approach to the temperature distribution. This distribution is calculated using the full equation of heat conduction. Moreover, the package allows for taking into account other types of data: seismic, petrological, thermal, etc. It should be noted that the hypothesis about isostatic equilibrium can be also used for other celestial bodies - e.g. Czechowski and LeliwaKopystyński (2013). The methods used in present studies are discussed below.

In the solid lithosphere the heat is transferred only by conduction, so the temperature distribution can be described by the heat flow equation in the form (e.g. Czechowski 1993; Turcotte and Schubert, 2002, Ch. 9): 
с $\rho \partial T / \partial t=\operatorname{div}(k(T, p, f) \operatorname{grad} T)+Q$

where $t[\mathrm{~s}]$ is the time, $T[\mathrm{~K}]$ is the temperature, $c\left[\mathrm{~J} \mathrm{~kg}^{-1} \mathrm{~K}^{-1}\right]$ is the specific heat at constant pressure, $\rho\left[\mathrm{kg} \mathrm{m}^{-3}\right]$ is the density, $k\left[\mathrm{~W} \mathrm{~m}^{-1} \mathrm{~K}^{-1}\right]$ is the coefficient of thermal conductivity (it may depend on the temperature, pressure and composition), and $Q\left[\mathrm{~W} \mathrm{~m}^{-3}\right]$ is the heat generation per unit volume. Nonlinear effects are included in the similar way to that used in Czechowski (2014), Puziewicz et al. (2012), and Losiak et al. (2015). The thickness of considered layer is $D=120 \mathrm{~km}$. It contains the lithosphere and part of the asthenosphere. The surface temperature $T_{0}$ and the heat flux at lower boundary $h f_{\mathrm{D}}$ are our boundary conditions.

Note also that density is a function of temperature and pressure given by the equation of state. In present paper, we use:

$$
\rho(p, T)=\rho(0,0)\left(1+p / K-\alpha\left(T-T_{0}\right)\right),
$$

where $\alpha\left[\mathrm{K}^{-1}\right]$ is the coefficient of thermal expansion and $K[\mathrm{~Pa}]$ is the bulk modulus. $K$ is a function of density and of elastic properties of the rock. Assuming that both Lame constants are equal (usually, they have similar values for many rocks), then velocity of $\mathrm{P}$ waves is:

$$
V_{\mathrm{P}}=(3)^{1 / 2} V_{\mathrm{S}} \text {. }
$$

Distributions of $V_{\mathrm{P}}$ and $V_{\mathrm{S}}$ are known in the considered sites. We use $V_{\mathrm{P}}$ to calculate the bulk modulus using the formula:

$$
K=(5 / 9) \rho\left(V_{\mathrm{P}}\right)^{2} \text {. }
$$

The isostatic equilibrium in our case means that there exists a level (known as a compensation level) in the asthenosphere where the value of hydrostatic pressure is the same below each block. It can be expressed by the condition:

$$
\int_{\text {surface }}^{\text {comp.level }} g(x) \rho(x) d x=\text { const, }
$$

where $g$ is the gravity acceleration. The integration is from the surface down to the compensation level. In the present research we do not consider geoid anomalies because it requires removing some components from the full spectrum of anomalies. Determining which components of the anomalies should be removed is somewhat subjective, therefore we do not use this possibility here. 


\section{Results and discussion}

Puziewicz et al. (2019) considered thermal conditions in the upper lithosphere in 4 chosen sites in Poland. We use some of the data published in their paper. However, in the present research we mainly investigate the problem of the deeper parts of the lithosphere, its thermal state, and the LAB position below Święciechowa and Września. We use also assumption about isostasy. Below, we present results for the following parameters of mantle in our model: $\alpha=310^{-5} \mathrm{~K}^{-1}, Q=810^{-8} \mathrm{~W} \mathrm{~m}^{-3}, \rho=3000 \mathrm{~kg} \mathrm{~m}^{-3}, c=1200 \mathrm{~J} \mathrm{~kg}^{-1} \mathrm{~K}^{-1}, k=3 \mathrm{~W}$ $\mathrm{m}^{-1} \mathrm{~K}^{-1}$. Note that given here values of $k$ are for the normal condition. The formula of Chapman and Forlung (1989) for $k$ as a function of temperature and pressure is used (see also Puziewicz et al. 2019 and Čermák et al. 1989).

\section{Problem of thermal steady state of the continental lithosphere}

The thermal steady state is assumed in many studies of the continental lithosphere (e.g., Puziewicz et al. 2012, 2019). A short discussion of this assumption is presented below. If the heat is transferred only by conduction then the temperature distribution is described by Eq. (1) (e.g. Czechowski 1993; 2019 a). Note that initially, the lithosphere, just after formation as a result of magmatic processes, is not in thermal equilibrium (i.e., the time derivative in Eq. (1) is not zero). An analysis of this equation indicates that thermal equilibrium is asymptotically reached with the time scale (e.g. Losiak et al. 2015; Puziewicz et al. 2019):

$$
\tau=d^{2} \rho c / k=d^{2} / \kappa,
$$

where $d$ is the characteristic spatial scale of the problem, and $\kappa\left[\mathrm{m}^{2} \mathrm{~s}^{-1}\right]=k /(\rho c)$ is the thermal diffusivity (e.g. Czechowski, 1993). The meaning of the spatial scale $d$ depends on the situation. It may be the smallest dimension of the considered structure (e.g., the thickness of lithosphere) or a wavelength of non-stationary component of the temperature distribution.

\section{Table 1}

Time scale $\tau$ (in Ma) according to Eq. (5) as a function

\begin{tabular}{|l|l|l|l|l|}
\hline of $d$ and $k$ for $c=1200 \mathrm{~J} \mathrm{~kg}^{-1} \mathrm{~K}^{-1}$ and $\rho=3000 \mathrm{~kg} \mathrm{~m}^{-3}$ \\
\hline$d[\mathrm{~km}]=$ & $k[\mathrm{~W} /(\mathrm{K} \mathrm{m})]=$ & 2 & 3 & 4 \\
\hline & 5 & 1,45 & 0,97 & 0,73 \\
\hline & 30 & 52,26 & 34,84 & 26,13 \\
\hline & 40 & 92,90 & 61,94 & 46,45 \\
\hline & 100 & 580,65 & 387,10 & 290,32 \\
\hline & 120 & 836,13 & 557,42 & 418,06 \\
\hline
\end{tabular}




\section{Preprint}

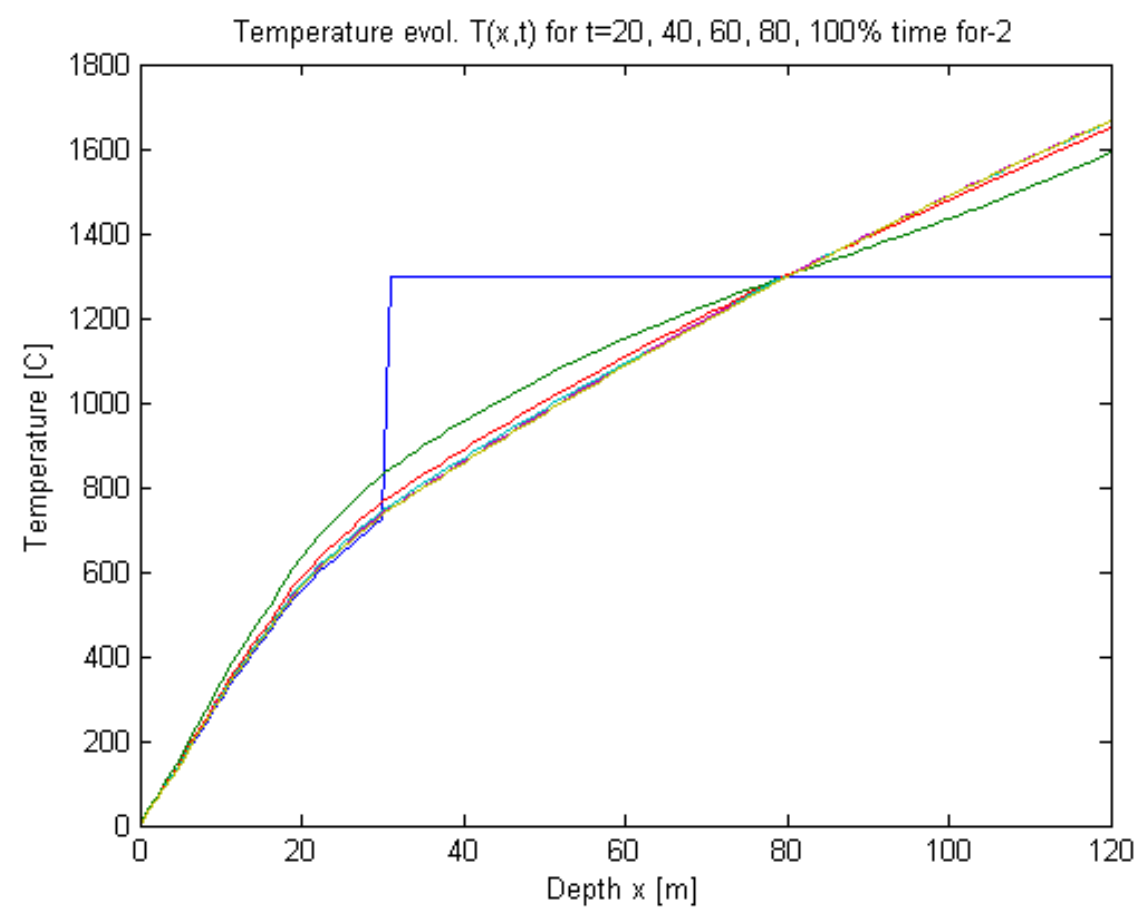

Fig.1 Evolution of geotherm for our model (see text for details). The colors correspond to the times: blue is for $0 \mathrm{Ma}$ (initial temperature - see text), green - $28 \mathrm{Ma}$, red - $56 \mathrm{Ma}$, cyan - 84 Ma, magenta - 112 Ma, grey - 140 Ma. The last three lines overlap.

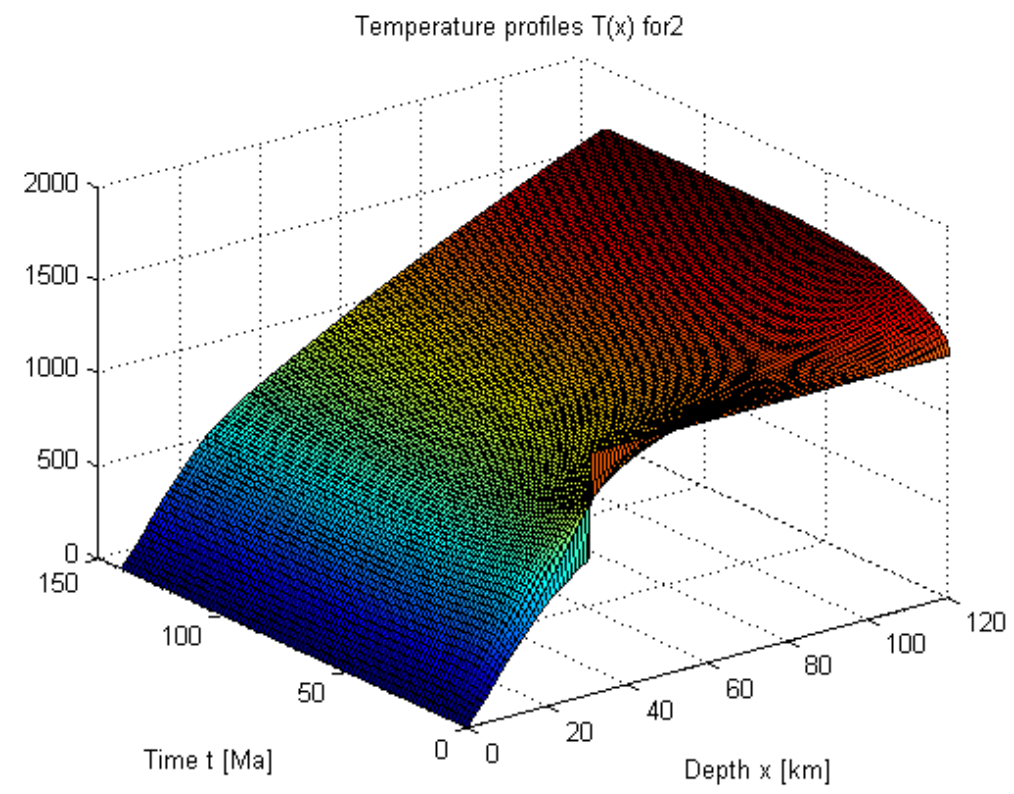

Fig.2 Evolution of thermal profile for the same model as in Fig.1. The 3 D surface represents changing continuously temperature profiles. 


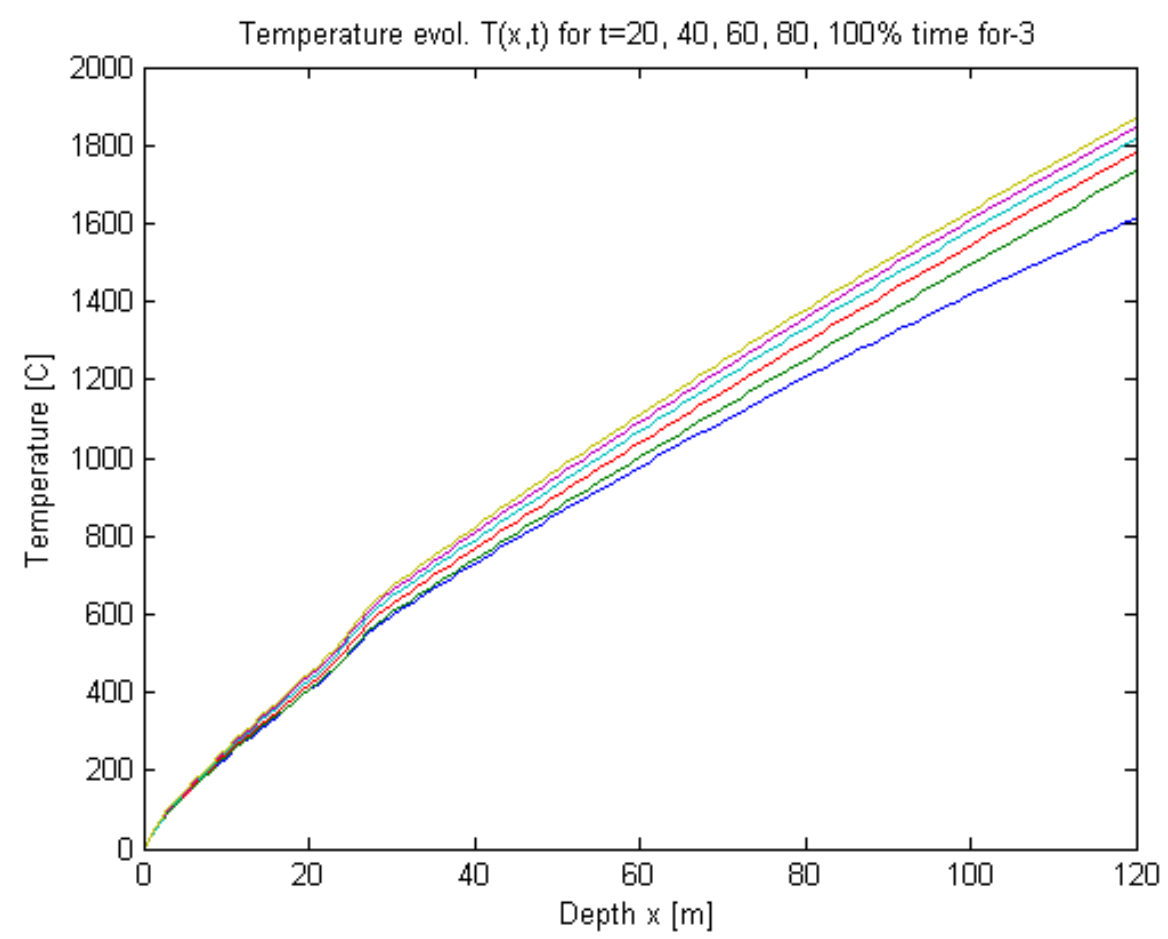

Fig. 3 Evolution of geotherm. The initial thermal steady state is disturbed by increasing $h f_{120}$ by $0.01 \mathrm{Wm}^{-2}$. The colors correspond to the times: blue - $0 \mathrm{Ma}$, green - $52 \mathrm{Ma}$, red - $104 \mathrm{Ma}$, cyan - $156 \mathrm{Ma}$, magenta - $208 \mathrm{Ma}$, grey - $260 \mathrm{Ma}$. Note that even after $260 \mathrm{Ma}$ the new steady state is not reached.

Figures 1 and 2 show an example of the thermal evolution of the lithosphere. The structure of crust corresponds to Rudna and $h f_{120}=0.032 \mathrm{~W} \mathrm{~m}^{-2}$ is assumed. The initial temperature for this model is calculated using the following procedure. The temperature profile corresponding to steady state has been calculated. This profile is used in the crust. Below the crust, we assume an inflow of the hot mantle matter (with temperature of $1300^{\circ} \mathrm{C}$ ). It is a simple model of complete rejuvenation of the mantle under the crust. We do not treat it as a real process in the considered region, but as an extreme model. It is used to indicate the possible duration of non-stationary thermal effects. The initial and a few later geotherms of this model are shown in Fig. 1.

Note three 'zones' in the this initial temperature profile: (1) the crust with a steady state temperature profile; (2) 'zone' with the temperature higher than for a steady state; and (3) 'zone' where the temperature is lower than the steady-state temperature. Therefore, we have two spatial scales here: the thickness of the considered domain $(120 \mathrm{~km})$ and the thickness of 'zones' $(\sim 40 \mathrm{~km})$. The characteristic time $\tau_{120}$ for the whole domain is about 10 


\section{Preprint}

times longer than for the zones $\tau_{\text {zone. }}$ Visible 'zones' have disappeared in several tens of millions of years, and after $\sim 90 \mathrm{Ma}$, the approximate steady state is reached. This is a shorter time than $\tau_{120}$ in Table 1, because the difference between the initial temperature distribution and the steady state distribution had mainly spatial scale $d \approx 40 \mathrm{~km}$. Component corresponding to $d \approx 120 \mathrm{~km}$ was significantly smaller. Figure 2 presents the evolution of temperature for the same model using 3D graphics.

Figure 3 shows another example of evolution. The crustal structure corresponds to Święciechowa. The initial thermal steady state has been disturbed by increasing $h f_{120}$ by 0.01 $\mathrm{W} \mathrm{m}^{-2}$. Now the evolution is slower. Even after $260 \mathrm{Ma}$, the new steady state has not been reached. It should be noted that the average true value of the coefficient of thermal conductivity in the mantle is $\sim 4 \mathrm{~W} \mathrm{~K}^{-1} \mathrm{~m}^{-1}$, because it increases with depth (see the next subsection).

\section{Thermal LAB}

Puziewicz et al. (2019) determined thermal condition in the crust and the upper lithosphere in four sites in Poland located approximately along the line beginning in Września (at the northeast end) and ending in Wilcza Góra (at the southwest end). They used various data: seismic data (from seismic profiles), petrological data (including data from laboratory measurements of rock parameters; e.g., radioactive elements concentration, thermal conduction coefficient, rock density, etc.) and heat flow data. The heat flow data has been corrected to remove disturbances due to climate change (i.e., the ice age). Eventually, Puziewicz et al. (2019) obtained reliable results regarding temperature distributions for the depth range studied.

The Września -Wilcza Góra line cuts a few tectonic discontinuities that divide the area into several distinct units. Therefore one can treat the region as a system of separate blocks. Each of these blocks can independently reach the isostatic equilibrium. We consider here two sites: Święciechowa and 'Września. Their structures of crust are substantially different.

In present paper we use some data published by Puziewicz et al. (2019). We use data concerning the crust and properties of rocks given in their Tables 2-5 and in Fig. 2. However, their density is treated as $\rho(0,0)$ in Eq. (2), i.e. the corrected value $\rho(p, T)$ is used in Eq. (1). Moreover, we assume different properties of rocks below MOHO. These properties are the parameters of our models (see above). In particular, we assume that the rocks below MOHO contain some heat sources. Note that even depleted mantle rocks contain some radioactive isotopes. The heat flow at the lower boundary $h f_{120}\left[\mathrm{~W} \mathrm{~m}^{-2}\right]$ is assumed to be: $0.03 \mathrm{~W} \mathrm{~m}^{-2}$ (for 
Września) and $0.035 \mathrm{~W} \mathrm{~m}^{-2}$ (for Święciechowa). Time dependent solutions and steady-state solutions are considered.

We want to obtain lithospheric models for considered sites that would ensure a correct (i.e., observed) heat flux on the surface and isostatic equilibrium. To achieve this, we have carried out several dozen numerical experiments, changing the parameters of the mantle in our models. We think that the models presented here are the most realistic ones.

$\mathrm{LAB}$ is often located in a zone with a potential temperature of $1300^{\circ} \mathrm{C}$. Here we also use this approach. The position of LAB is determined by the intersection of the $1300^{\circ} \mathrm{C}$ adiabat with the geotherm. For the adiabat we use here the formula (see e.g., Czechowski, 1993):

$d T / d p=\alpha T /(\rho c)$,

or

$d T / d x=\alpha g T / c$.

In the range of considered depths and values of parameters $\alpha, \rho, c$, the adiabat is practically a straight line with low inclination - Fig. 4.

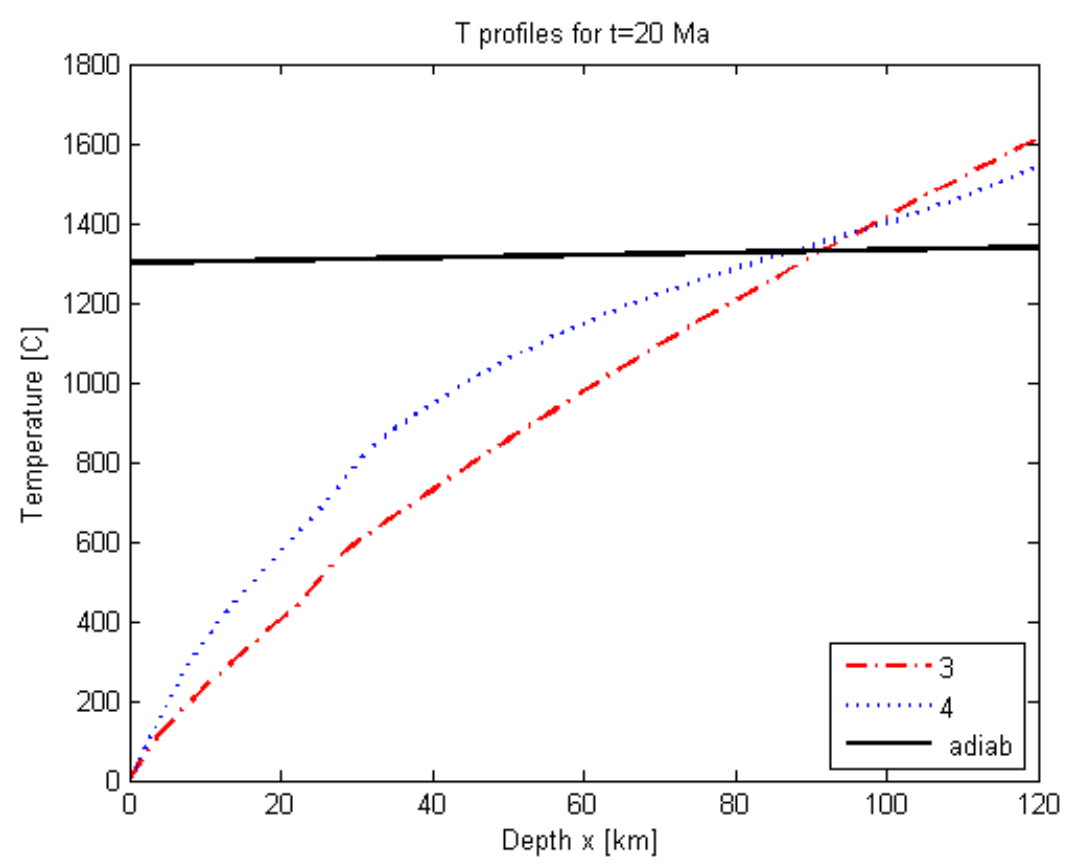

Fig.4. Profiles of temperature for 2 considered sites (see text) after $20 \mathrm{Ma}$ of evolution. The same parameters of the mantle is used for Figs. 5-9. Black line represents $1300^{\circ} \mathrm{C}$ adiabat. Positions of thermal LAB are given by intersections of the adiabat and geotherms. 


\section{Preprint}

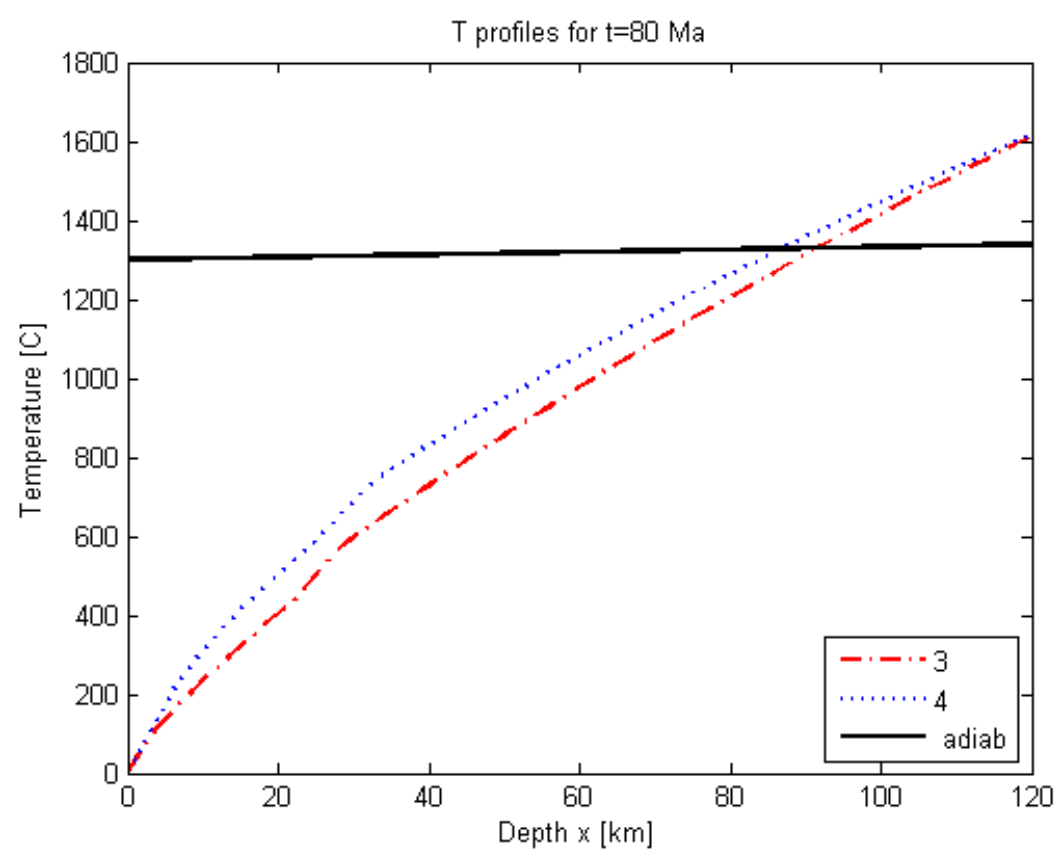

Fig.5. Profiles of temperature after $80 \mathrm{Ma}$ of evolution. The rest is as in Fig. 4.

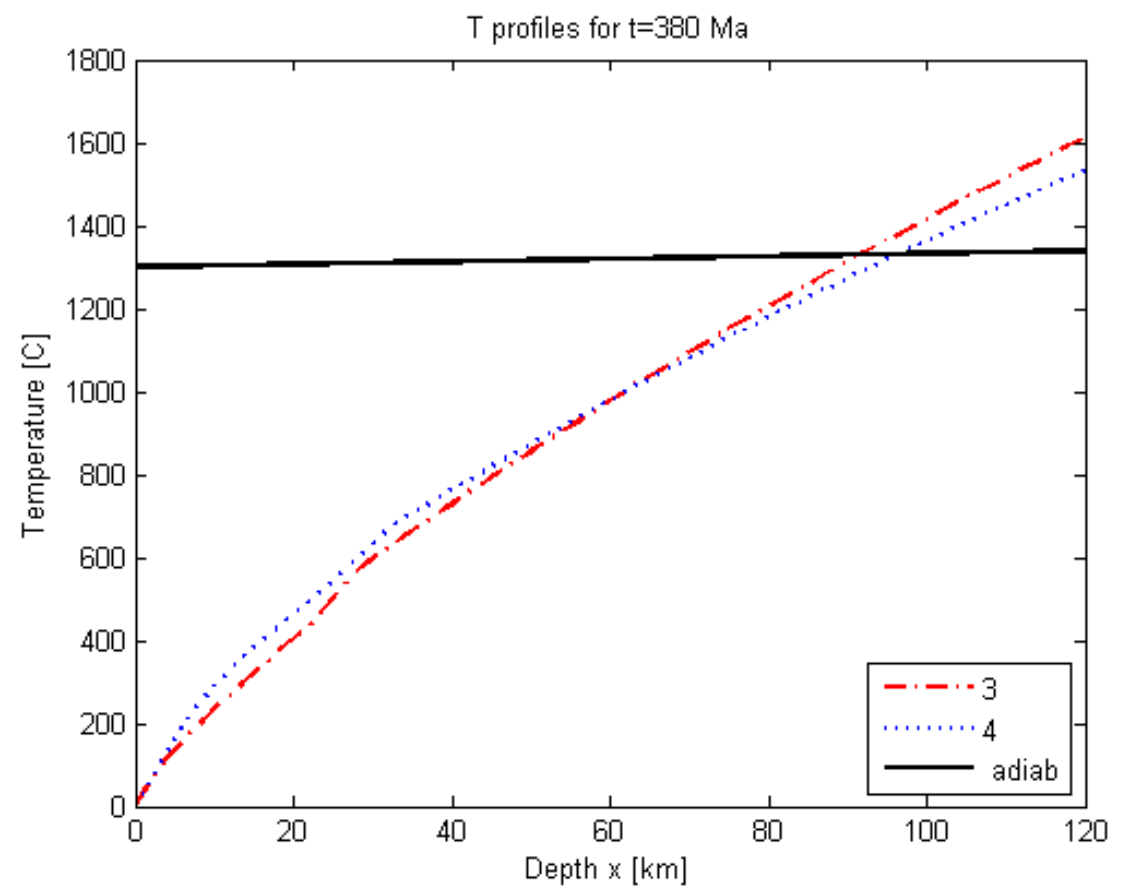

Fig.6. Profiles of temperature after $380 \mathrm{Ma}$ of evolution. The rest is as in Fig. 4. 


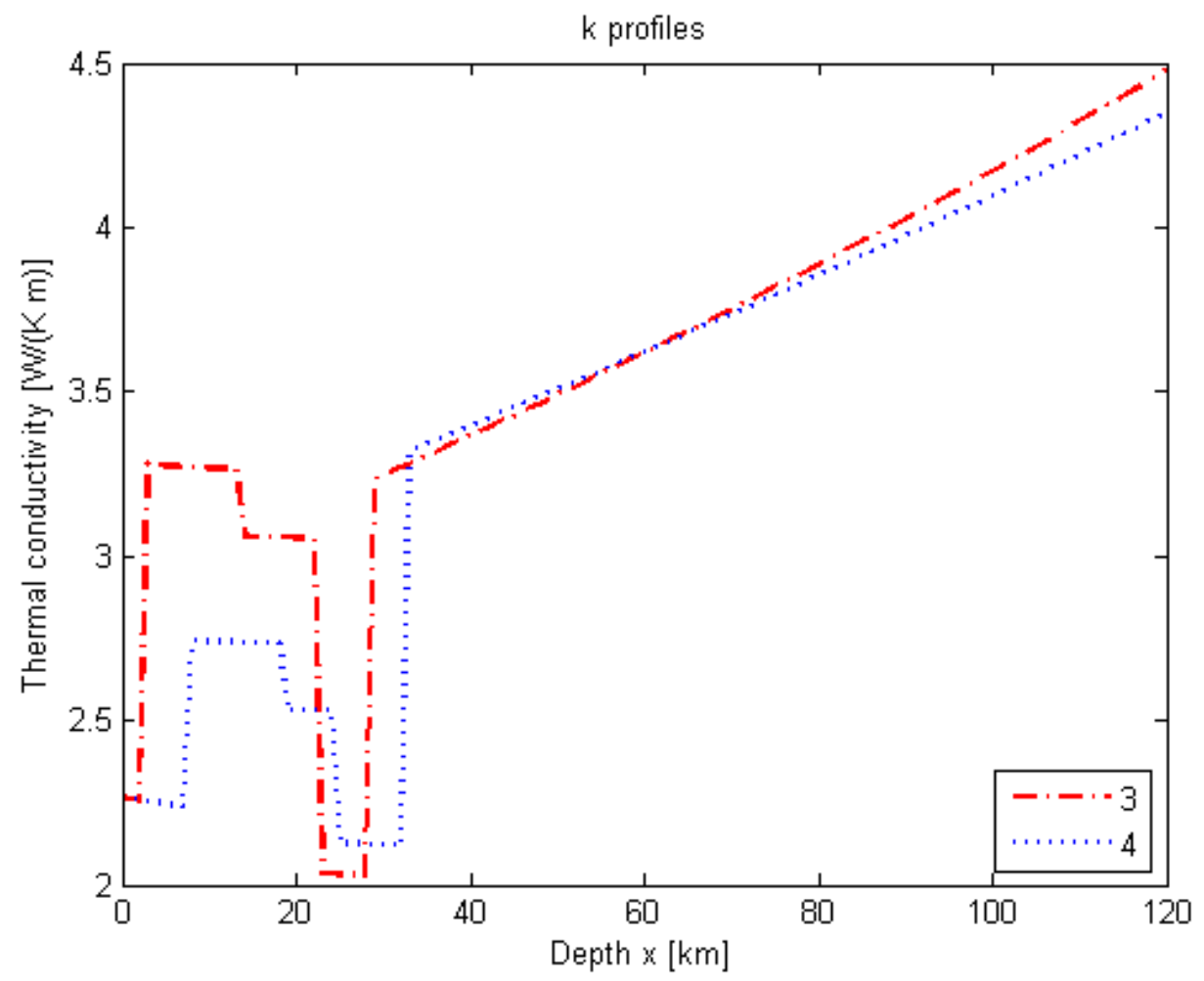

Fig.7. Profiles of coefficient of thermal conduction for 2 considered sites (see text) for thermal steady state.

Figures 4, 5, 6 show geotherms for 2 sites considered here (line 3 stands for Święciechowa, 4 for Września). The same mantle parameters are used as above. The intersection of $T(x)$ profile with the adiabat shows the location of LAB. This rather low depth of LAB suggests that coefficient of thermal conduction in the lower lithosphere is rather high. We use $k=3 \mathrm{~W} \mathrm{~m}^{-1}$ $\mathrm{K}^{-1}$ in normal conditions. Fig. 7 indicates that $k$ increases with depth up to $\sim 4.5 \mathrm{~W} \mathrm{~m}^{-1} \mathrm{~K}^{-1}$ at $120 \mathrm{~km}$.

The location of the thermal LAB in Central and Eastern Europe was determined in several investigations, e.g. Geissler et al. (2010), Tesauro et al. (2009), Hamza and Vieira (2012), Priestley and McKenzie (2013), Bielik (1999). Unfortunately, the results given in these papers sometimes are not compatible with each other.

Differences between the LAB position determined by different methods (e.g., thermal LAB and seismic LAB) are easily understood, as they essentially concern different physical properties of the rocks. The relationship between the different types of LABs is further complicated by the possibility of two types of lithosphere. Czechowski and Grad (2018) indicated that position of LAB is determined by the ratio (melting 
temperature)/(temperature) and an invariant of the stress tensor. They found that LAB resulting from changes of shear stress could be a transient, time-dependent structure.

However, positions of the thermal LAB are also often different in different papers. This applies not only to the LAB position itself (which depends on the value of the adopted parameters, e.g., on the thermal conductivity $k$ in the mantle), but also to the shape of the boundary. Note, that the shape should be less dependent on the value of parameters. Therefore, we think that further improvement of LAB determination methods would be useful. This can be achieved by using additional data and more advanced numerical models. We try both options. See also: Majorowicz et al. (2019), Grad et al. (2018).

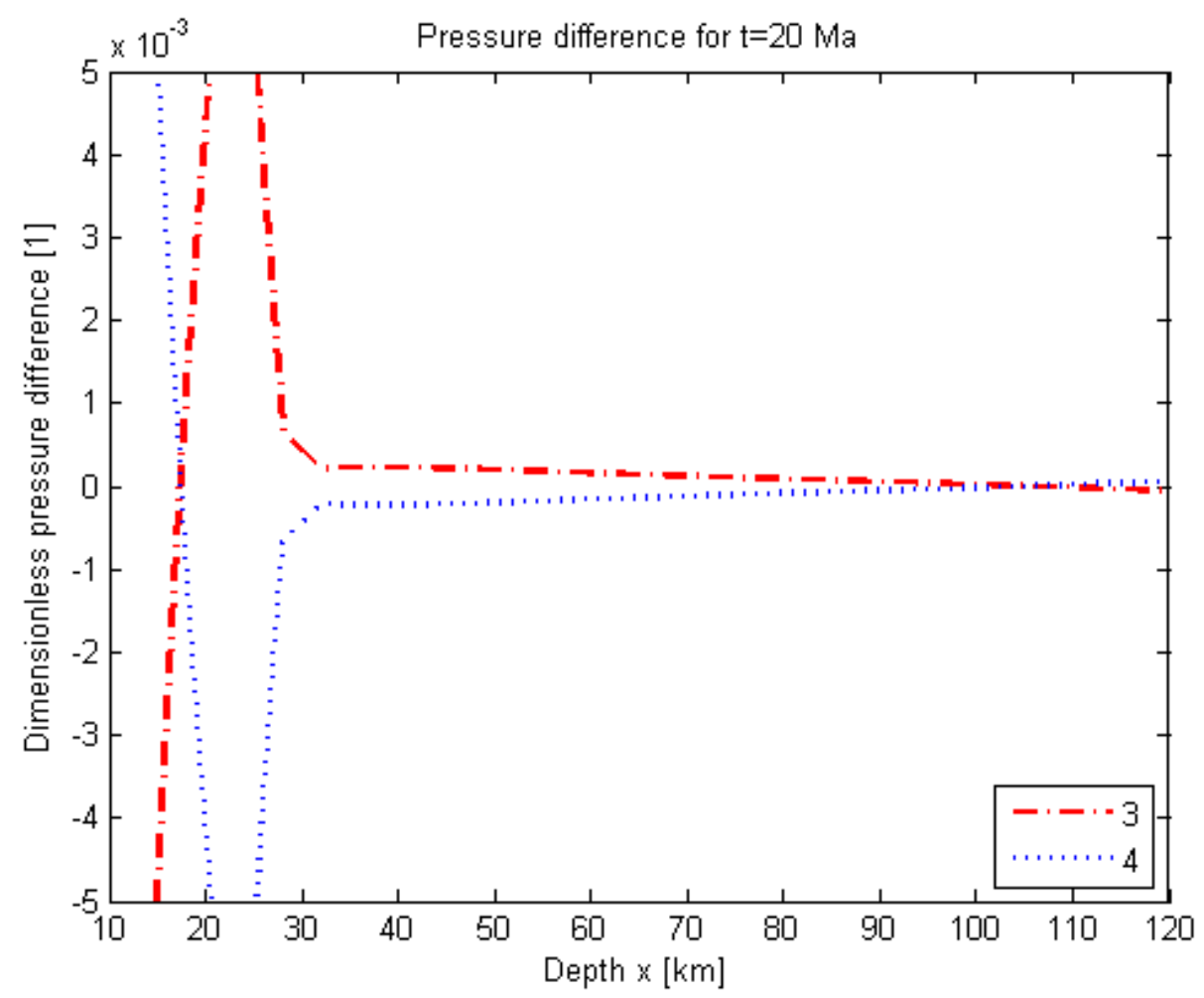

Fig. 8. Relative pressure difference $p_{\text {rel }}$ after $20 \mathrm{Ma}$ of evolution. Note the large differences of $p_{\text {rel }}$ in the crust and only small differences below MOHO. At $\sim 110 \mathrm{~km}$ lines for 3 and 4 are intersecting indicating full compensation. 
Preprint

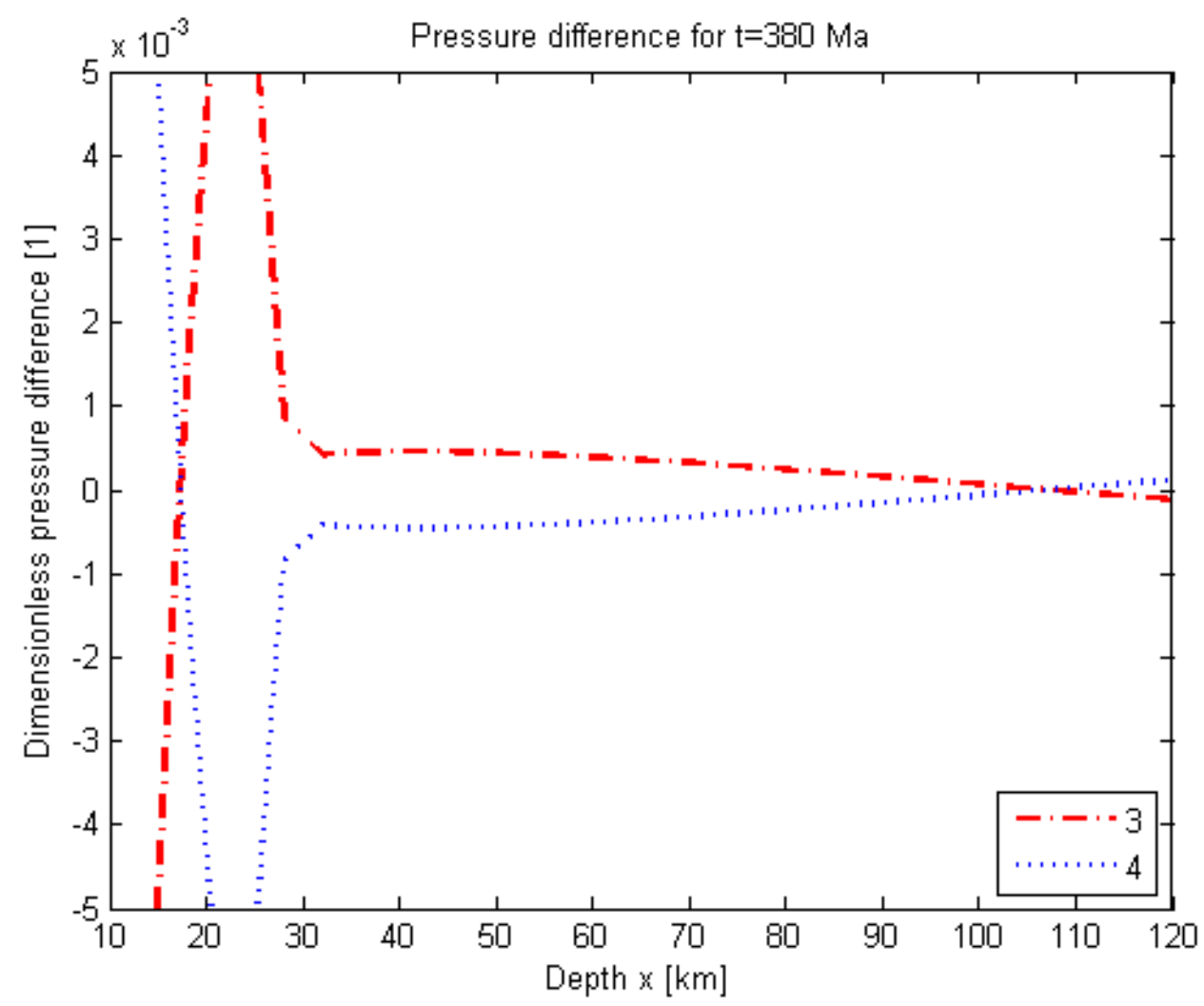

Fig. 9. Relative pressure difference $p_{r e l}$ for thermal steady state. There are only minor difference comparing to Fig. 8.

\section{Compensation level}

The state of isostasy of the lithospheric blocks means that at some depth in the asthenosphere there is a surface where the pressure is constant regardless of the place (at least constant in the range of a given region). This is possible, provided that the matter in the asthenosphere has liquid properties and is at rest - Czechowski (2019 a). Therefore we calculate the weight of the lithosphere column (of $1 \mathrm{~m}^{2}$ cross-section) in the considered sites. This weight depends on the density of rocks. The density depends on the type of rocks and on the temperature and pressure distributions - see Eq. (2).

Figures 8 and 9 show relative a dimensionless pressure deviation $p_{r e l}$ as a function of depth (line 3 is for model of Święciechowa and line 4 is for Września). It is calculated according to formula:

$p_{\text {rel }}=($ pressure $-($ average pressure $)) /($ average pressure $)$, 


\section{Preprint}

where 'average pressure' denotes distribution of the pressure averaged for 2 considered sites. In the crust $p_{\text {rel }}$ is high (several percent), but at MOHO it drops sharply below $\sim 0.3 \%$. This means that the crust (at least in the considered sites) is close to the isostatic equilibrium, although it is in the lithosphere, the rocks of which do not show liquid properties. Czechowski (2019 a) suggests that this state close to isostasy may be a remnant of the period when the LAB was directly under the crust. Figs 8 and 9 show also that at the depth of $\sim 110 \mathrm{~km}$ the pressure values for Września and Święciechowa are equal, so we could treat this depth as the location of the exact compensation level. This is below the thermal LAB, which does not raise any objections, because isostatic LAB is determined by other properties of the lithosphere. However, note that the difference of $p_{\text {rel }}$ below MOHO is very small. It indicates that this 'exact' compensation level is very sensitive to density differences.

\section{Conclusions}

We have found that our programs allow the use of different data to determine the position of LAB and some parameters of the mantle. It is possible to use data obtained by geological or geophysical methods (e.g., by the receiver function analysis, Wilde-Piorko, 2015, or data concerning the seismic LAB, Grad et al. 2014). It is only necessary to find a mathematical relationship between those data and thermal parameters or density, because they are used in our model. It should be noted that the magnetic properties and the electrical conductivity of rocks are also related to thermal conditions. Of course, the accuracy of our method depends on the sensitivity of the used data to the thermal conditions or density of rocks.

More specific conclusions can be found below.

1. The calculations indicate that the assumption about the steady state temperature distribution in the continental lithosphere may sometimes be unjustified but usually does not lead to significant errors.

2. The system (1-2) can be used to determine different thermal and/or elastic properties of the lithosphere. In particular, we have found that the average thermal conductivity of mantle is $\sim 4$ $\mathrm{W} \mathrm{m}^{-1} \mathrm{~K}^{-1}$.

3. By using LABWA2015, we are able to establish more reliable LAB positions in selected sites.

4. The crust blocks in the considered sites are close to the isostasy, indicating that once the level of compensation was close to MOHO. 
5. The position of the 'exact' compensation level in asthenosphere (found at $\sim 110 \mathrm{~km}$ ) is sensitive to density differences.

The above conclusions should be treated as preliminary. We continue to prepare of extended paper (e.g. Czechowski 2019 b). In a few months it will be sent for publication.

\section{Acknowledgments}

This work was partially supported by Narodowe Centrum Nauki (Poland's National Science Centre) grant 2011/01/B/ST10/06653. Computer resources of Interdisciplinary Centre for Mathematical and Computational Modeling of University of Warsaw were also used in the research.

\section{References}

Bielik, M., 1999. Geophysical features of the Slovak Western Carpathians: a review. Geol. Quaterly 43 (3) :251-262

Čermák, V., Šafanda, J., Guterch, A. 1989. Deep temperature distribution along three profiles crossing the Teisseyre-Tornquist tectonic zone in Poland. Tectonophysics 164, $151-163$

Chapman, D.S., Furlong, K.P. 1992. The thermal state of the lower crust. In: Fountain DM, Arculus RJ, Kay RM (eds) Developments in geotectonics. Continental lower crust, vol 23. Elsevier, Amsterdam, pp 179-199.

Czechowski, L. 1993. Theoretical Approach to Mantle Convection. In: Teisseyre, R., Czechowski, L., and Leliwa-Kopystyński, J. (Eds.), Dynamics of The Earth's Evolution, vol 6 of the monographic series Physics and Evolution of the Earth's interior. R. Teisseyre (ed. of the series) Elsevier, Amsterdam, pp. 161-271, 1993.

Czechowski, L. 2014. Some remarks on the early evolution of Enceladus. Planetary and Space Science 104, Issue PB, 185-199. 
Czechowski L., 2018. Determination of the Lithosphere-Asthenosphere Boundary using program LABWA2015. EarthArXiv, doi: 10.17605/OSF.IO/UCVSX, https://eartharxiv.org/ucvsx/

Czechowski L., 2019 a. Mantle flow and determining position of LAB using assumption about isostasy. PAGEOPH, https://link.springer.com/article/10.1007/s00024-019-02093-8 .

Czechowski, L. 2019 b. Lithosphere-Asthenosphere Boundary below East European Craton and properties of lower lithosphere. Geophysical Research Abstract. Vol. 21, EGU2019-8327. https://meetingorganizer.copernicus.org/EGU2019/EGU2019-8327.pdf

Czechowski L., and M. Grad, 2018. Two mechanisms of formation of asthenospheric layers. arXiv:1802.06843 [physics.geo-ph], https://arxiv.org/abs/1802.06843

Czechowski, L., Leliwa-Kopystynski, 2013. Remarks on the Iapetus' bulge and ridge. Earth, Planets and Space. Volume 65, 8, 929-934

Fullea, J.U., Fernàndez, M, Zeyen, H., 2006. Lithospheric structure in the AtlanticMediterranean transition zone (southern Spain, northern Morocco): A simple approach from regional elevation and geoid data. Geoscience 338, 140-151.

Geissler, W.H., Sodoudi, F., Kind, R. 2010. Thickness of the central and eastern European lithosphere as seen by S receiver functions. Geophys J. Int. 181, 604-634

Grad, M., Tira, T., Olsson, S., Komminaho, K., 2014. Seismic lithosphere-asthenosphere boundary beneath the Baltic Shield. GFF 136, 4, 581-598

Grinc, M., Zeyen, H., Bielik, M., 2014. Automatic 1D integrated geophysical modelling of lithospheric discontinuities: a case study from Carpathian-Pannonian Basin region. Contributions to Geophysics and Geodesy,Vol. 44/2, 115-131.

Hamza, V.M., Vieira, F.P., 2012. Global distribution of the lithosphere- asthenosphere boundary: a new look. Solid Earth 3:199-212 
Losiak, A., Czechowski, L., Velbel, M.A., 2015. Ephemeral liquid water at the surface of the martian North Polar Residual Cap: Results of numerical modeling. Icarus Volume 262, December 01, 2015, Pages 131-139.

Krysiński, L., Grad, M., Mjelde, R., Czuba, W., Guterch A. 2013. Seismic and density structure of the lithosphere-asthenosphere system along transect Knipovich Ridge-Spitsbergen-Barents Sea - geological and petrophysical implications. Polish Polar Research, Vol. 34, 111-138.

Krysiński, L., S. Wybraniec, and M. Grad, 2015. Lithospheric density structure study by isostatic modelling of the European geoid. Studia Geophysica et Geodaetica. 59, 212-252.

Majorowicz, J., M. Polkowski,'M. Grad. 2019. Thermal properties of the crust and the lithosphere-asthenosphere boundary in the area of Poland from the heat flow variability and seismic data. International Journal of Earth Sciences, https://doi.org/10.1007/s00531-01801673-8

Priestley, K., and McKenzie, D., 2013. The relationship between shear wave velocity, temperature, attenuation and viscosity in the shallow part of the mantle. Earth Planet Sci Lett 381:78-91

Puziewicz, J., Czechowski, L., Krysiński, L., Majorowicz, J., Matusiak-Małek, M., 2012. Lithosphere thermal structure at the eastern margin of the Bohemian Massif: a case petrological and geophysical study of the Niedźwiedź amphibolite massif (SW Poland)International Journal of Earth Sciences 101 (5), 1211-1228

Puziewicz, J., L. Czechowski, M. Grad, J. Majorowicz, A. Pietranik, J. Safanda, 2019. Crustal lithology vs. thermal state and Moho heat flow across the NE part of the European Variscan orogen: a case study from SW Poland. International Journal of Earth Sciences: https://doi.org/10.1007/s00531-018-01674-7 5.

Turcotte, D.L and Schubert G., 2002. Geodynamics. Cambridge University Press, $2^{\text {nd }}$ ed., pp. 456. 


\section{Preprint}

Tesauro M, Kaban MK, Cloetingh SAPL (2009) A new thermal and rheological model of the European lithosphere. Tectonophysics 476(3-4):478-495

Wilde-Piórko., M. 2015. Crustal and upper mantle seismic structure of the Svalbard Archipelago from the receiver function analysis. Polish Polar Research, 36, 2, 89-107. 